Copyright (C) 2016 by Academic Publishing House Researcher

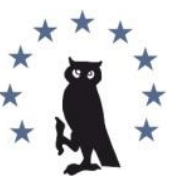

Published in the Russian Federation

European Researcher

Has been issued since 2010.

ISSN 2219-8229

E-ISSN 2224-0136

Vol. 112, Is. 11, pp. 550-555, 2016

DOI: 10.13187/er.2016.112.550

www.erjournal.ru

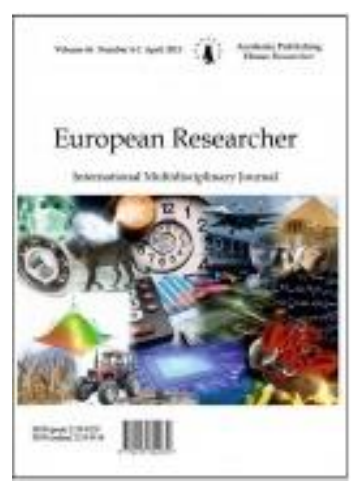

UDC 378

\title{
The Problem Analysis of Existing FSES of Higher Education for the Enlarged Group of Specialties "the Service and Tourism"
}

Marina A. Maznichenko a, Nataliya I. Neskoromnykh a, *

a Sochi State University, Russian Federation

\begin{abstract}
The article presents the results of aspect analysis of the current federal state educational standards of higher education for the enlarged group of specialties "Service and tourism". There are analyzed the conformity of educational standards of higher education to the requirements of employers, the requirements for development results, to the structure and terms of realization of educational programs of undergraduate/graduate. The authors outline the key problems for each aspect, also identify the relevant disadvantages. This analysis will help us to find solutions to the identified key problems and make possible the designing/updating of education standards.

Keywords: the personnel training for the sphere of service and tourism, the federal state standards of higher education of the third generation, the enlarged group of specialties "the service and tourism".
\end{abstract}

\section{1. Актуальность}

Прежде чем приступить к проектированию/актуализации Федеральных государственных образовательных стандартов высшего образования третьего поколения (ФГОС ВО $3^{+}$) по направлениям подготовки бакалавров и магистров «Гостиничное дело» $\mathrm{c}$ учетом профессиональных стандартов (ПС), необходимо выполнить аспектный анализ действующих ФГОС ВО по укрупненной группе направлений (УГН) подготовки «Сервис и туризм» и выявить ключевые проблемы по каждому аспекту. Такой анализ позволит в дальнейшем прийти к поиску способов решения выявленных ключевых проблем.

Объектом исследования явились входящие в УГН «Сервис и туризм» действующие ФГОС ВО 3+: 43.03.01 Сервис (уровень бакалавриата) (утверждён Министерством образования и науки РФ 20.10.2015 г. № 1169), 43.04.01 Сервис (уровень магистратуры) (утверждён Министерством образования и науки РФ 17.08.2015 г. № 835); 43.03.02 Туризм (уровень бакалавриата) (утверждён Министерством образования и науки РФ 14.12.2015 г. № 1463), 43.04.02 Туризм (уровень магистратуры) (утверждён Министерством образования и науки РФ 17.08.2015 г. № 837); 43.03.03 Гостиничное дело (уровень бакалавриата) (утверждён Министерством образования и науки РФ 4.12.2015 г. № 1432), 43.04.03 Гостиничное дело (уровень магистратуры) (утверждён Министерством образования и науки

\footnotetext{
${ }^{*}$ Corresponding author

E-mail addresses: maznichenkoma@mail.ru (M.A. Maznichenko), nesknatali@mail.ru (N.I. Neskoromnykh)
} 
РФ 3.09.2015 г. № 954) (далее - действующие образовательные стандарты или ФГОС ВО 3+). Цель исследования: провести проблемный анализ действующих ФГОС ВО 3+ по УГН подготовки «Сервис и туризм».

Задачи научной работы: 1) выявить достоинства действующих образовательных стандартов; 2) выявить недостатки, снижающие качество высшего образования в сфере сервиса и туризма, и соответствующие им ключевые проблемы; 3) соотнести выявленные ключевые проблемы с возможными способами их решения.

\section{2. Материалы и методы}

Для достижения поставленных целей и задач использовались методы: анализ ФГОС BO, научных публикаций, в которых анализируются и оцениваются образовательные стандарты, экспертные оценки.

\section{3. Обсуждение и результаты}

Опираясь на исследования, в которых раскрываются теоретические основы разработки ФГОС ВО и ООП (А.А. Марголис [1], И.В. Бушуева, Л.И. Скабеева, Ю.М. Лагусев [2], [3] и др.), мы провели аспектный анализ образовательных стандартов, входящие в УГН подготовки «Сервис и туризм», по следующим направлениям: 1) соответствие ФГОС ВО требованиям работодателей; 2) требования к результатам освоения и к структуре образовательной программы (ОП) бакалавриата/магистратуры; 3) требования к условиям реализации образовательной программы. По каждому направлению анализа выявленные проблемы были упорядочены и представлены в виде «дерева проблем» с выделением ключевых из них. Представим результаты анализа по каждой проблемной плоскости.

Первое направление анализа («соответствие ФГОС ВО требованиям работодателей») связано с выявлением положительных сторон и существующего дисбаланса между требованиями к специалистам со стороны работодателей и качеством подготовки выпускников вузов по УГН «Сервис и туризм».

К положительным сторонам отнесены:

1. Закрепление в ФГОС ВО $3^{+}$обязательного требования привлечения к образовательному процессу представителей работодателей.

2. Еще большее усиление профессиональной направленности ОП и взаимосвязи результатов обучения с требованиями ПС.

3. Разделение квалификаций на академическую и прикладную («академический бакалавр» и «прикладной бакалавр»), что соответствует потребностям рынка труда.

4. ФГОС ВО 3+ внесли ясность и четкость в определение области профессиональной деятельности и объектов деятельности выпускников. Уточнена и расширена область профессиональной деятельности, «что необходимо для формирования единой системы образовательного пространства» [4, с. 126].

5. ФГОС ВО 3+ по сравнению с образовательными стандартами второго поколения повышают свободу вуза в формировании и реализации ОПОП, а значит - предоставляют возможности отвечать реальным нуждам сектора сервиса и туризма, потребностям регионального развития конкретного сектора экономики в области профессионального образования, устанавливать взаимозаинтересованные отношения с потенциальными работодателями, использовать механизмы внешнего оценивания.

К ключевым недостаткам и проблемам отнесены:

1. Недостаток: построение и структурирование образовательных стандартов выполнено без должного учета набора профессиональных функций и профессиональных действий, выделенных в результате функционального анализа профессиональной деятельности в ПС. Проблемы: недостаточная согласованность ФГОС ВО и ПС; отставание содержания профессиональной подготовки от потребностей современной индустрии сервиса и туризма; дисгармония между уровнем подготовки выпускников вузов и ожиданиями работодателей; проблема перевода требований ПС в требования ФГОС ВО и ПООП.

2. Недостатки: единый список профессиональных компетенций в образовательных стандартах для всех вузов России вне зависимости от потребностей экономики регионов и территориального рынка труда; несоответствие некоторых профессиональных компетенций 
ПС («компетентностная избыточность» и «дефицит» профессиональных компетенций). Проблемы: невозможность изменения вузом перечня профессиональных компетенций, заданных в образовательных стандартах, в зависимости от востребованности специалистов сферы сервиса и туризма в различных регионах; затруднения разработчиков ОПОП в оптимизации перечня профессиональных компетенций из-за недостаточной разработанности научно-методических основ этого процесса; построенные на основе действующих образовательных стандартов ОПОП не работают на опережение, не ориентированы в должной степени на возникновение новых профессиональных компетенций или переакцентирование прежних.

3. Недостаток: сосредоточение основного внимания в ФГОС ВО «Туризм» на туроперейтинге, что привело к подмене широкого понимания туризма [5, с. 70]. Проблемы: переизбыток подготовки персонала для турфирм; неудовлетворенный спрос на специалистов в других секторах туриндустрии.

Для решения этих проблем необходимо разработать и утвердить все необходимые ПС для работников сферы сервиса и туризма, спроектировать ФГОС ВО $3^{++}$с учетом соответствующих ПС. Новые ФГОС ВО $3++$ должны иметь рамочный характер: позволять вузам гибко и оперативно реагировать на региональные особенности индустрии сервиса и туризма при разработке ПОПО.

Второе направление анализа связано с изучением требований к результатам освоения и к структуре ОП бакалавриата/магистратуры.

К положительным сторонам отнесены:

1. Построение действующих образовательных стандартов на основе принципа ориентации на результат, что выражается в переориентации ФГОС ВО с содержания (обязательный учебный материал) и процесса (продолжительность курса) на результаты обучения (компетенции).

2. Компетентностный подход, лежащий в основе ФГОС ВО 3+, требует обеспечить целенаправленное проведение предметной подготовки будущих специалистов сферы сервиса и туризма в русле достижения общего интегрального результата освоения ОПОП с заданным качеством (уровнем освоения заявленных компетенций выпускника) и позволяет оптимально сочетать теоретическую и практическую составляющие обучения, интегрируя их.

4. Изменился состав компетенций, выступающих в качестве требований к результатам освоения ОП: количество формируемых программой бакалавриата компетенций сократилось.

3. В образовательных стандартах нашел отражение «функциональный» подход к профессиональным компетенциям, ориентированный на способность выпускника решать ряд задач в соответствии с видами профессиональной деятельности и со стандартами выполнения работы.

4. Задана менее жесткая регламентация структуры ОП, что содержит значительные возможности по инновационному преобразованию системы высшего образования. В ФГОС ВО приведены рамочные требования к структуре ОП в форме интервала трудоемкости отдельных блоков программы, что дает возможность вузу вводить при необходимости иные общие трудоемкости освоения ОП.

5. Согласно действующим ФГОС ВО, структура ОП бакалавриата/магистратуры включает обязательную (базовую) и вариативную (формируемую участниками образовательных отношений) части. Такая структура ОП дает возможности для развития профильного образования в рамках направления подготовки, а это в свою очередь позволяет учитывать отраслевую специфику и требования бизнес-сообщества.

6. ФГОС ВО задают модульную структуру ОП, что «позволяет гибко реагировать на запросы времени и работодателей и оперативно обновлять или заменять конкретные модули при изменении требований к специалисту вследствие изменений в технологиях и организации труда, обеспечивая качество подготовки специалистов на конкурентоспособном уровне» [6]; а также варьировать модули в соответствии со спецификой организации образовательного процесса, тем самым повысить гибкость ОП.

К ключевым недостаткам и проблемам отнесены:

1. Недостатки: нечеткость формулировок, количественная избыточность и недостаточность результатов освоения ОП - компетенций выпускников; недостаточная 
выраженность преемственности компетенций на уровнях подготовки бакалавров и магистров; неполное соответствие результатов освоения программ с указанными в ФГОС ВО областями, объектами, задачами и видами профессиональной деятельности. Проблемы: проблема конструирования общего «ядра» профессиональной подготовки специалистов для сферы сервиса и туризма на основе анализа требований образовательных стандартов к результатам освоения ОП и квалификационных требований ПС; проблема сохранения преемственности ОП разных уровней высшего образования через требования к результатам освоения ОП по направлениям подготовки бакалавров и магистров.

2. Недостатки: в образовательных стандартах отсутствуют единые для всей УГН подготовки «Сервис и туризм» перечни универсальных (метапредметных) компетенций, отражающих ожидания современного общества в части социально-личностной позиции выпускника, а также ожидания личности в части потенциальной готовности к самореализации и саморазвитию; перечень общепрофессиональных компетенций не в полной мере отражает запросы рынка труда в части владения выпускником основами профессиональной деятельности с учетом ее динамичного развития, а также ожидания личности к потенциальным возможностям профессионального роста. Проблемы: проблема обеспечения преемственности на разных ступенях высшего образования; проблема сопряжения ФГОС ВО и ПС.

3. Недостаток: формальный подход к реализации модульного принципа формирования ОП, при котором модуль не рассматривается и не предстает в качестве единицы формирования трудовых функций и профессиональных действий и не дополняется для осуществления и отработки профессиональных действий существенной долей практики в специально организованной лабораторно-учебной среде и в условиях реальной организации/предприятия (базы практики); искусственное объединение в модуль близких по целям учебных дисциплин. Проблемы: структура и содержание ОПОП, разработанных на основе $Ф Г О С$ ВО $3+$, остаются в предметной парадигме и не могут оперативно и адекватно реагировать на потребности рынка труда; недостаточная практическая подготовленность выпускников вуза к осуществлению отдельных профессиональных функций или набору взаимосвязанных трудовых действий, направленных на решение типовых профессиональных задач.

3. Недостаток: в действующих ФГОС ВО задано соотношение объемов базовой и вариативной частей ОП. Проблема: вуз не имеет возможность изменить соотношение базовой и вариативной частей ОП, тем самым повысить ее гибкость.

4. Недостаток: «перекос» в сторону академичности по отношению к практическому обучению в процессе реализации ОП ВО [7]. Проблема: недостаточная практическая подготовленность выпускников вуза к осуществлению отдельных профессиональных функций и профессиональных действий; отсутствие практического опыта выполнения конкретных профессиональных задач с учетом профиля профессиональной подготовки и квалификации.

Для решения этих проблем необходимо:

- оптимизировать результаты освоения ОПОП на основе задания общих для каждого образовательного уровня универсальных компетенций и общих для УГНП «Сервис и туризм» общепрофесиональных компетенций (соответствующих укрупненным трудовым действиям, дифференцированным по уровням подготовки бакалавров и магистров), а также приведения в соответствие существующего списка осваиваемых компетенций со списком компетенций, заданных соответствующими ПС, и требованиями работодателей и объединений работодателей;

- изменить структуру ОП за счет существенного увеличения сроков практики, необходимых для полноценного освоения профессиональных действий и освоения целостной профессиональной деятельности;

- расширить полномочия вузов в области формирования ОПОП и закрепить такую возможность в ФГОС ВО.

Третье направление анализа («требования $\kappa$ условиям реализации образовательной программы») связано с изучением оптимальности кадровых условий, требований к материально-техническому и учебно-методическому обеспечению ОПОП, к финансовым условиям реализации ОП.

К положительным сторонам отнесены: 
1. В ФГОС ВО 3+ усилены и четко разграничены требования к условиям реализации ОП. Условия подразделяются на четыре группы: кадровое, материально- техническое, учебно-методическое и финансовое обеспечение.

2. Из ФГОС ВО исключена таблица 2 «Структура ООП бакалавриата/магистратуры», что обеспечило свободу вузов в выборе образовательных технологий.

3. В ФГОС ВО включены требования по обеспечению условий для обучения инвалидов и лиц с ограниченными возможностями здоровья, что обеспечило общедоступность высшего образования для инвалидов и лиц с ОВ3, способствующего их социализации и социальной адаптации.

4. Установлены пределы применения электронного и сетевого обучения, обучения на базовых кафедрах. Предполагается, что использование этих образовательных технологий в образовательном процессе значительно увеличит доступ ко всем видам ресурсов (информационным, материально-техническим, кадровым, финансовым и пр.) и приведет к повышению качества профессиональной подготовки выпускников.

К ключевым недостаткам и проблемам отнесены:

1. Недостатки: сформулированные в ФГОС ВО 3+ требования к условиям реализации ОП не позволяют поднять на качественной иной уровень практическую и теоретическую подготовку бакалавров/магистров, гарантируя их готовность к осуществлению профессиональной деятельности в области индустрии гостеприимства в соответствии с требованиями ПС; условия реализации ОП не четко ориентированы на показатели, установленные для вузов при прохождении государственной аккредитации. Проблема: создание необходимых и достаточных условий подготовки выпускников вузов.

Для решения этих проблем необходимо: разработать и включить в ФГОС ВО общие требования к условиям реализации программ для УГН.

\section{4. Заключение}

ФГОС ВО 3+, входящие в УГНП «Сервис и туризм», содержат значительный потенциал для инновационного развития системы высшего образования и предоставляют большую свободу вузам в формировании ОПОП с учетом ПС, что увеличивает возможности вузов точнее и оперативное реагировать на запросы рынка труда. Однако эти действующие образовательные стандарты не лишены существенных недостатков, исправление которых в конечном итоге может привести к положительным изменениям в качестве подготовки выпускников.

\section{Примечания}

1. Марголис А. А. Требования к модернизации основных профессиональных образовательных программ (ОПОП) подготовки педагогических кадров в соответствии с профессиональным стандартом педагога: предложения к реализации деятельностного подхода в подготовке педагогических кадров // Психологическая наука и образование. 2014. Т. 19. № 3. С. 105-126.

2. Бушуева И. В., Скабеева Л. И. О современных практико-ориентированных подходах к разработке образовательных программ подготовки магистров по направлению «Гостиничное дело» // Вестник Ассоциации вузов туризма и сервиса. 2016. Т. 10. № 1. С. 12-20.

3. Скабеева Л. И., Лагусев Ю. М. Современные тенденции формирования основных образовательных программ подготовки бакалавров и магистров по направлению «Гостиничное дело» // Вестник Ассоциации вузов туризма и сервиса. 2016. Т. 10. № 1. С. 4-11.

4. Мальцева С. Г., Теодорович М. В. Сравнительный анализ государственных стандартов трех поколений высшего профессионального образования для сферы туризма // Ученые записки. 2014. № 8. С. 124-128.

5. Колотова Е. В. Современные подходы к подготовке кадров для туристской индустрии // Научный вестник МГИИТ. 2015. № 3. С. 67-80.

6. Макарова Е. В., Угрюмова С. Д. Проблематика и противоречия ФГОС третьего поколения // Вестник Дальрыбвтуза. 2015. № 5. С. 59-66.

7. Морозова Н. С. Взаимодействие вузов и работодателей по подготовке кадров для индустрии туризма // Профессиональное образование в сфере туризма как условие 
повышения качества туристских услуг: матер. междунар. науч.-практ. конф. (Москва, 1314 декабря 2012 г.). М.: ФГБОУ ВПО «РГУТИС». 2012. С. 219-224.

\section{References}

1. Margolis A. A. Trebovaniya $\mathrm{k}$ modernizatsii osnovnykh professional'nykh obrazovatel'nykh programm (OPOP) podgotovki pedagogicheskikh kadrov v sootvetstvii $\mathrm{s}$ professional'nym standartom pedagoga: predlozheniya $\mathrm{k}$ realizatsii deyatel'nostnogo podkhoda $\mathrm{v}$ podgotovke pedagogicheskikh kadrov // Psikhologicheskaya nauka i obrazovanie. 2014. T. 19. № 3 . S. $105-126$.

2. Bushueva I. V., Skabeeva L. I. O sovremennykh praktiko-orientirovannykh podkhodakh $\mathrm{k}$ razrabotke obrazovatel'nykh programm podgotovki magistrov po napravleniyu «Gostinichnoe delo» // Vestnik Assotsiatsii vuzov turizma i servisa. 2016. T. 10. № 1. S. 12-20.

3. Skabeeva L. I., Lagusev Yu. M. Sovremennye tendentsii formirovaniya osnovnykh obrazovatel'nykh programm podgotovki bakalavrov i magistrov po napravleniyu "Gostinichnoe delo» // Vestnik Assotsiatsii vuzov turizma i servisa. 2016. T. 10. № 1. S. 4-11.

4. Mal'tseva S. G., Teodorovich M. V. Sravnitel'nyi analiz gosudarstvennykh standartov trekh pokolenii vysshego professional'nogo obrazovaniya dlya sfery turizma // Uchenye zapiski. 2014. № 8. S. 124-128.

5. Kolotova E. V. Sovremennye podkhody k podgotovke kadrov dlya turistskoi industrii // Nauchnyi vestnik MGIIT. 2015. № 3. S. 67-80.

6. Makarova E. V., Ugryumova S. D. Problematika i protivorechiya FGOS tret'ego pokoleniya // Vestnik Dal'rybvtuza. 2015. № 5. S. 59-66.

7. Morozova N. S. Vzaimodeistvie vuzov i rabotodatelei po podgotovke kadrov dlya industrii turizma // Professional'noe obrazovanie v sfere turizma kak uslovie povysheniya kachestva turistskikh uslug: mater. mezhdunar. nauch.-prakt. konf. (Moskva, 13-14 dekabrya 2012 g.). M.: FGBOU VPO «RGUTIS». 2012. S. 219-224.

УДК 378

Проблемный анализ действующих ФГОС высшего образования
по укрупненной группе направлений подготовки «Сервис и туризм»

Марина Александровна Мазниченко а, Наталия Ивановна Нескоромных а , *

a Сочинский государственный университет, Российская Федерация

Аннотация. В статье представлены результаты аспектного анализа действующих Федеральных государственных образовательных стандартов высшего образования по укрупненной группе направлений «Сервис и туризм». Проанализированы соответствие образовательных стандартов высшего образования требованиям работодателей, требования к результатам освоения, к структуре и условиям реализации образовательной программы бакалавриата/магистратуры. Обозначены ключевые проблемы по каждому аспекту и выявлены соответствующие недостатки. Такой анализ позволит в дальнейшем прийти к поиску способов решения выявленных ключевых проблем и проектированию/актуализации образовательных стандартов.

Ключевые слова: подготовка кадров для сферы сервиса и туризма, федеральные государственные стандарты высшего образования третьего поколения, укрупненная группа направлений подготовки «Сервис и туризм».

\footnotetext{
${ }^{*}$ Корреспондирующий автор

Адреса электронной почты: maznichenkoma@mail.ru (М.A. Мазниченко), nesknatali@mail.ru (Н.И. Нескоромных)
} 